Volume 8(2) (2011), 111-122

Copyright (c) Equinox Publishing Ltd

Sheffield

http://equinoxpub.com

DOI: 10.1558/cam.v8i2.111

\title{
Doctors' questions as displays of understanding
}

\section{ARNULF DEPPERMANN AND THOMAS SPRANZ-FOGASY}

Institut für Deutsche Sprache, Mannheim, Germany

\begin{abstract}
Based on German data from history-taking in doctor-patient interaction, the paper shows that the three basic syntactic types of questions (questions fronted by a question-word (w-questions), verb-first (V1) questions, and declarative questions) provide different opportunities for displaying understanding in medical interaction. Each syntactic questionformat is predominantly used in a different stage of topical sequences in history taking: w-questions presuppose less knowledge and are thus used to open up topical sequences; declarative questions are used to check already achieved understandings and to close topical sequences. Still, the expected scope of answers to yes/no-questions and to declarative questions is less restricted than previously thought. The paper focuses in detail on the doctors' use of formulations as declarative questions, which are designed to make patients elaborate on already established topics, giving more details or accounting for a confirmation. Formulations often involve a shift to psychological aspects of the illness. Although patients confirm doctors' empathetic formulations, they, however, regularly do not align with this shift, returning to the description of symptoms and to biomedical accounts instead. The study shows how displays of understanding are responded to not only in terms of correctness, but also (and more importantly) in terms of their relevance for further action.
\end{abstract}

Keywords: conversation analysis; doctor-patient interaction; questions; formulations; understanding in interaction

\section{Introduction}

Starting with the patient's initial presentation of his/ her problem, the basic task in doctor-patient interaction consists of arriving at a diagnosis by collecting all relevant information about the patient's problem and its history. From the very beginning of the medical encounter, this task is guided by the doctor's questions, which provide the agenda of the interaction (Heritage and Clayman 2010). Agenda-setting by questions embraces the topics to be talked about and the actions to be performed by the patient, such as describing symptoms, justifying beliefs and clarifying prior turns (Manning and Ray 2002). Previous research has dealt extensively with how the doctor's questions constrain and prefigure the patient's response and how patients react to different kinds of questions (Boyd and Heritage 2006; Frankel 1995; Heritage 2001; Heritage and Robinson 2011; Lalouschek 2005; Spranz-Fogasy 2005; Stivers 2007; Stivers and Heritage 2001). Questions thus are mainly analysed regarding their prospective potentials.

Boyd and Heritage (2006), however, point out that questions do more than only set topical and action agendas: questions embody presuppositions about facts; they establish preferences for the patient's response; and they convey the doctor's epistemic stance concerning possible answers. Our paper takes up this line of research. We focus on how doctors use different linguistic question-types in order to display how they understand the patient's previous turns. Based on German data from doctor-patient interactions (section 2), we show that the three basic syntactic types of questions (questions fronted by a question-word ( $w$-questions), verb-first (V1) questions, and declarative questions) provide different opportunities for displaying understanding in medical interaction (section 3). Each question type

\section{eevinoxonline}


is characterized by a specific relationship between what the doctor treats as being already understood and known and what s/he still needs to know from the patient. Moreover, each question type embodies specific assumptions about the possibility and probability of propositions to hold. We describe how the three types are used in topical sequences and how they are responded to by patients. Then we focus in more detail on how doctors use formulations of patients' previous turns as declarative questions (section 4). Special attention is given to explicative declarative questions by which doctors formulate empathetic perceptions of the patient's feelings in order to tease out psychological aspects of the illness.

\section{Context of inquiry and corpus}

This study is part of a larger research project at the Institute for the German Language (Mannheim) which is concerned with 'verbal and communicative displays of understanding in interaction' (http://www. ids-mannheim.de/prag/verstehen/home_eng.html; see Deppermann and Schmitt 2009). The findings in this paper are based on 13 audio-taped first medical interviews conducted by four different doctors. The encounters lasted a total of $2 \mathrm{~h} 6 \mathrm{~min} 43 \mathrm{sec}$, ranging from $2 \mathrm{~min} 9 \mathrm{sec}$ to $17 \mathrm{~min} 55 \mathrm{sec}$ per interaction. Doctors produced a total of 535 questions (an average of one question every $14.2 \mathrm{sec}$ ).

\section{Three question formats}

History taking in medical interaction is mainly governed by doctors' questions (Stivers and Majid 2007). Different syntactic formats of questions are used to display different degrees of understanding (3.1). Their distribution over the course of history taking reflects the increase of understanding on the doctor's part (3.2), and the patients' responses take this into account (3.3).

\subsection{Question formats as understanding displays}

While being designed to elicit patients' answers, questions inevitably presuppose already existing knowledge and assumptions on the doctor's part (Heritage and Clayman 2010). Presuppositions may be derived from professional knowledge, world knowledge or prior information about the patient. Presuppositions, however, can also display some understanding of prior turns of the patient (mostly, the immediately preceding turn). The design of the question then is at least in part motivated by the interactional process so far. In what follows, we will discuss how different syntactic formats of questions can be used as displays of understanding. As in most languages, in German there are three basic syntactic question formats: $w$-questions, V1-questions and declarative questions.

\subsubsection{W-questions (engl. wh-questions)}

These questions are fronted by a question-word, which always starts with the phoneme /w/ in German: 'wer' ('who'), 'was' ('what'), 'warum' ('why'), 'wie' ('how'), 'wann' ('when'), etc.

Example 1 (IA_MR_03_00:48-00:52)
44 P: ich hab gleich ANGST I immediately get afraid
$45<<$ dim > wenn ich so was dann HAB, if I get such things
46 ne? (n_bisschen).> right? A little bit
$\rightarrow 47$ D: wovor ham sie denn ANGST- What are you afraid of

The patient states that her hoarse voice (she reported before) makes her feel afraid. The doctor then asks her to elaborate on what she fears. With the question, the doctor shows that he has understood the emotional meaning of the symptoms for the patient, but asks her to be more specific about the precise nature of her fears to get a fuller picture of the motivational background of the patient's feelings.

$W$-questions elicit information on a property of an event or a state of affairs. Linguistically, the $w$-word refers to a thematic role (Dowty 1989), such as agent, patient, cause, instrument, time, place, etc., which has yet to be instantiated in the doctor's frame of knowledge regarding the patient's problem. $W$-questions thus address categories which need to be instantiated, while the topic itself ('fear') and some predication pertaining to it ('patient fears something') are being presented as already known and understood. The turn-initial position of the $w$-word marks the turn as a question and it indexes the category of the kind of knowledge which is missing.

\subsubsection{Verb-first (V1) questions}

These questions have the finite verb in the first position of the sentence. They are often termed 'yes/nointerrogatives' (Heritage and Clayman 2010), because they project yes or no as type-conforming answer (Raymond 2003; but see sect. 3.3).

\section{eevinoxonline}


Example 2 (AA_BI_03_00:02-00:19)

09 P: ich habe seit DREI tagen einen

äh- (-) !FIN!ger-

well since three days I have a

uh finger

10

wo ich nicht WEIß- (.)

where I do not know

11 was ich damit MAchen soll; what I should do with

$12 \quad(0.8)$

13 P: also ich- (.)

well I

14 wenn ich- (.)

if $I$

15 gEstern abend hab ich n_BRIEF

geschrieben-

yesterday evening I wrote

a letter

16 da is er also ganz DICK

geworden- (--)

then it grew very fat

17 D: m::h

uhm

$18 \mathrm{P}$ : und das is als ob hier ein- (.) and that is as if here a (0.1)

19 ne NAdel oder irgendwas drin wär. a needle or something else was inside

$\rightarrow 20$ D: HAM se_n Unfall gehabt?

did you have an accident

The patient reports about swellings and pain at one of her fingers. The doctor then asks her if she had an accident, obviously proposing this to be a possible cause of the symptoms. The positive polarity of the question establishes a preference for a confirming answer. Like $w$-questions, the turn-initial position of the verb marks the turn syntactically as a question.

V1-questions imply a possible proposition which is presented as being uncertain. V1-questions thus address the epistemic issue of the existence of some referents or of the validity of the proposition and of the proposed relation between thematic roles as it is expressed in the question. By their syntactic form, V1-questions embody more presupposed knowledge than $w$-questions: the speaker does not indicate that some slot in his/her frame of knowledge is uninstantiated, but $\mathrm{s} /$ he proposes a possible instantiation, its epistemic status, however, still being unsettled. In this way, the speaker implicitly claims to know that one of two alternative propositions which are incompatible with each other will hold. The difference in the distribution of knowledge between $w$ - and V1-questions is evidenced by their projective properties: while $w$-questions require the respondent to provide a categorization or description of the missing elements him/herself, V1-questions project a yes/no-answer (but see sect. 3.3). That is, the questioner has already set up the possible answers; the task of the respondent remains only to choose among them. Note, however, that in many cases the question implies a bias towards one of the alternatives and thus some preference for the corresponding answer. This is most obvious with 'negative polarity questions', such as did you have any other problems (Heritage and Robinson 2011), which imply the expectation of a 'no problem'-answer (Stivers and Heritage 2001).

\subsubsection{Declarative questions}

These questions have the syntax of a declarative sentence, i.e. they are not syntactically marked as questions (Heritage and Clayman 2010: 140). Understanding declarative sentences as necessitating a response depends on prosodic, sequential, pragmatic and epistemic features (Stivers and Rossano 2010). ${ }^{1}$ Still, their meaning is often ambiguous: it can become a subject of negotiation whether they amount to a question, an acknowledging or confirming statement, or a challenge. In our study we included declarative sentences as questions, if they were subsequently treated (by the patients) or clarified (by the doctors) as such.

Example 3 (AA_BI_03_00:44-00:47)

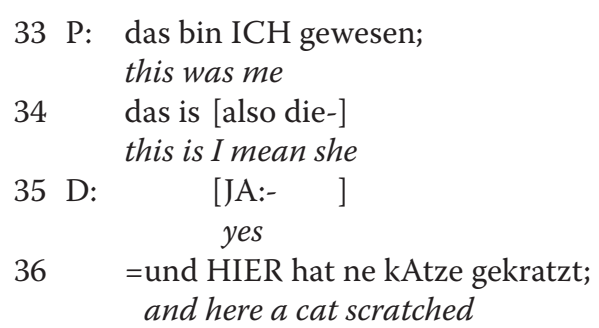

The doctor and the patient talk about injuries of the patient's hand. The patient states that she caused one of them herself. Looking at her hand, the doctor then asks whether a cat caused the other wound. Both the declarative mode and the positive polarity of her turn index that the doctor rates her assumption as highly probable and that she strongly projects its confirmation by the patient. This is further corroborated by turn-initial and, which projects an affiliative expansion of the prior turn.

Declarative questions embody a still enhanced presumption of knowledge. They present a statement as not only being possible, but most probable. Like with V1-questions, the questioner displays that s/he purports to know the possible options, but declarative questions imply that one of them is most likely. So, unlike V1-questions, they are not a request for the truth-value of a proposition, but they present

\section{eevinoxonline}


an assumption for ratification, establishing a strong preference for confirmation. In terms of understanding, doctors use declarative questions as formulations of patients' prior turns in order to ground their understanding as an intersubjective fact (Clark and Schaefer 1989), thus facilitating topical closure and interactional progression to next-positioned matters (cf. Beach and Dixson 2001).

In sum, while questions prospectively ask for knowledge which is missing, retrospectively they presuppose some knowledge which is treated as being already understood from the patient's prior turns. More specifically, each syntactic type of question displays a specific distribution of what is assumed to be understood and known, and which knowledge is still missing. The three syntactic question-types imply an increasing level of presupposition, ranging from thematic knowledge over the presupposition of knowing relevant alternatives to the assumption of some probable state of affairs (see Table 1).

\subsection{Distribution of question formats}

In our corpus, the three types of questions are distributed as follows (see Table 2):

Table 2 shows that most doctors' questions are declarative questions, which embody strong assumptions about what is the case and which are merely presented for confirmation. These assumptions can be derived from professional knowledge, e.g. about causes and co-variation of symptoms and illnesses, from common sense knowledge, and from previous information about the patient. However, a large part of these questions amounts to understanding checks which display how the doctor has understood the patient's previous turns.

The three question types do not only constitute a cognitive scale of increasing presumption of knowledge and understanding. Typically, they also appear in a consecutive order in topically bounded sequences in doctor-patient interaction. That is, the exploration of topics starts with a $w$ - or a V1-question and ends with declarative questions which formulate the upshot of the sequence from the doctor's point of view and seek the patient's confirmation. The increasing use of question types which presuppose a higher degree of understanding and certainty over the course of topical sequences thus reflects the process of the interactional accomplishment of understanding and knowledge of anamnestic facts and the path of arriving at diagnostic hypotheses (Spranz-Fogasy 2010). It shows that during topical sequences doctors incrementally delimit the range of relevant problems and symptoms by their mode of questioning, increasingly constraining the scope of possible answers (Stivers and Heritage 2001; Heritage and Clayman 2010).

\subsection{Patients' reactions to different formats of questions}

According to prior work on question formats (Mishler 1984; Raymond 2003; Rost-Roth 2006) we would predict that more than $80 \%$ of the doctors' questions, i.e. V1- and declarative questions, restrict the scope of projected answers essentially to a choice between yes and no. In our data, however, we found

Table 1: Syntactic question types and the distribution of missing and presupposed knowledge

\begin{tabular}{|l|l|l|}
\hline Question-Type & Kind of missing knowledge & $\begin{array}{l}\text { Missing knowledge (italics) } \\
\text { Presupposed knowledge(plain text) }\end{array}$ \\
\hline W-Question & Uninstantiated thematic role & $\begin{array}{l}\text { wovor haben sie denn angst? } \\
\text { what makes you afraid? }\end{array}$ \\
\hline V1-Question & $\begin{array}{l}\text { Existence/truth/validity of } \\
\text { proposition }\end{array}$ & $\begin{array}{l}\text { ham se_n unfall gehabt? } \\
\text { did you have an accident? }\end{array}$ \\
\hline Decl-Question & Confirmation of statement & $\begin{array}{l}\text { und hier hat ne katze gekratzt } \\
\text { and here a cat scratched }\end{array}$ \\
\hline
\end{tabular}

Table 2: Distribution of syntactic question types

\begin{tabular}{|l|l|l|}
\hline Question-type & Absolute number $(N=499)$ & Relative frequency \\
\hline W-Question & 90 & $18 \%$ \\
\hline V1-Question & 136 & $27 \%$ \\
\hline Declarative Question & 273 & $55 \%$ \\
\hline
\end{tabular}


surprisingly small differences in the lengths of the patients' answers. Although $w$-questions elicit the longest answers (on average 13.2 words/answer), declarative questions are responded to almost with the same amount of elaboration (12.48 words/ answer); V1-questions also tend to elicit answers which are much longer than just yes/no (10.2 words/ answer). These numbers suggest that the contrast between open-ended and closed questions (Mishler 1984) seems to be 'ideologically' overrated, not taking into account the patients' power to negotiate what was made relevant by a question and their capacity to resist narrow expectations (Stivers and Heritage 2001; Spranz-Fogasy 2010). Moreover, third-position renewals of V1- and declarative questions after simple yes/no-answers show that doctors themselves often expect a more elaborate answer (see Example 4 below). Doctors often are not only interested in a type-conforming response (Raymond 2003), but in addition, they expect some account which clarifies, justifies or provides further details concerning the confirmation.

Still, an answer which does not restrict itself to yes or $n o$ can also be a dispreferred response, pointing to trouble with the task of answering. Indeed, while only $3.6 \%$ of $w$-questions were responded to in a dispreferred format, $14.2 \%$ of the declarative questions and $36.4 \%$ of the V1-questions got a dispreferred response. These findings seem to show that especially V1-questions often confront the patient with the problematic presupposition of two alternatives which are not applicable from the patient's point of view. Therefore, they are often responded to with categorical modifications and accounts which reject the presuppositions being made with the V1-question. Declarative questions fare better in this respect because they are often understanding checks which repeat or formulate prior turns of the patient (see section 4).

\section{Declarative questions as displays of understanding}

Doctors use (partial) repeats and formulations (Heritage and Watson 1979) of what they take the patient to have meant in order to check their understanding and to make sure that common ground is established on which further talk can be based (Clark and Schaefer 1989). Still, repeats and formulations may be designed by doctors and treated by patients as devices to elicit more topical talk by the patient. ${ }^{2}$ (Partial) repeats and formulations are thus used as declarative questions which invite the patient to elaborate on his/her prior turns and to do so in a way which attends to the relevancies selected by the doctor by his/her repeat or formulation. Since declarative utterances are not syntactically marked as questions, they do not exhibit 'response-mobilizing features' (Stivers and Rossano 2010) in terms of turn-design. Therefore, it often is a matter of negotiation whether formulations are to be treated as questions in terms of making a response by the patient conditionally relevant. It is those cases in which doctors and/or patients treat them as requiring an elaborate response that we deal with in what follows.

Doctors' understandings of the patient which are expressed by declarative questions vary in terms of their inferential properties. They range from repetitions with identical wording (save deictic adaptations) to inferential formulations which reinterpret the patient's statements according to an alternative frame of reference (cf. Antaki 2008). Declarative questions thus express varying degrees of how the doctor transforms the patient's turns according to his/ her practical relevancies of understanding. We can distinguish three practices of declarative questions, which are situated along this inferential continuum:

- repeating declarative questions (4.1)

- paraphrasing declarative questions (4.2)

- explicative declarative questions (4.3)

\subsection{Repeating declarative questions}

Doctors repeat (parts of) patients' turns in order to index what the doctor regards as a result of the topical sequence which is to be retained. In this way, they are used as devices for securing a shared understanding of the topically most relevant statements of the patient from the doctor's point of view. In addition, they are often used to elicit an elaboration on the topic by the patient in terms of providing additional detail, reasons or causes for the repeated statement.

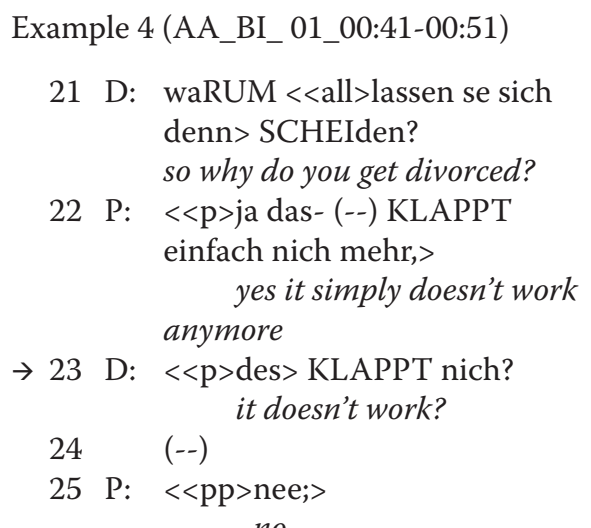

\section{eevinoxonline}


26 D: Aber das: (.) MACHT ihnen ja MÄCHtig <<h $>$ zu SCHAF $\downarrow$ fen nich?> but this bothers you PRT quite a lot, doesn't it? wollen SIE denn:,= do you want to

$28 \mathrm{P}:=<<\mathrm{p}>$ ne [s_(VON mir) $>$ ] no it's from my part or does your husband want to

30 P: (-) ne (wir wolln_s) BEIde; no (we) both (want it)

$\rightarrow 31$ D: (-) BEIde. both

$32 \quad(--)$

33 D: waRUM $\downarrow$ denn; so why

In line 23 , the doctor partially repeats the patient's prior statement (line 22) in order to seek confirmation. The repeat ' $<<p>$ des $>$ KLAPPT nich?' ('it doesn't work') omits the modal word 'einfach' ('simply') and the temporal specification ('nicht' ('not') instead of 'nicht mehr' ('no more')), thus reducing the patient's turn to its semantic core content. Obviously, however, the repeat was not only produced to ground the patient's prior statement intersubjectively, but to invite some elaboration by the patient. This is evidenced by the fact that the doctor pursues the topic of why the patient gets divorced in line $26 \mathrm{ff}$. by asking the patient in more depth regarding several aspects of the divorce. In line 31, the doctor again uses a partial repeat of the prior turn of the patient ('beide', 'both') to elicit an expansion, which the patient, however, does not offer. The doctor clarifies her expectation again by a thirdturn follow-up question in line 33 ('warum denn', 'so why'), by which she asks for reasons of the divorce. Line 23 thus is an example for a declarative question where the third position following the response attests that the questioner expects an answer which is not restricted to a simple yes or no (as is, in fact, provided by the patient), but an elaboration of the topic. When, as in this case, repeats and formulations are not successful in eliciting an elaboration, the pursuit for a more elaborated response is continued by syntactically marked $w$ - and V1-questions (see lines 27, 29,33), which specify the focus of the expected elaboration more precisely by a question word or by presenting an alternative. In this way, the project of elaborative questioning, which was already indexed as possibly, but not necessarily, relevant by the repeating declarative question, is unambiguously made clear by $w$ - and V1-questions. The partners' participation in this project is made obligatory by the conditional relevance for elaboration which these other two syntactic types of questioning establish.

\subsection{Paraphrasing declarative questions}

In contrast to repetitions, with paraphrasing declarative questions the doctor replaces the patient's wording with his own formulation designed to capture the gist of the patient's turns (cf. Heritage and Watson 1979).

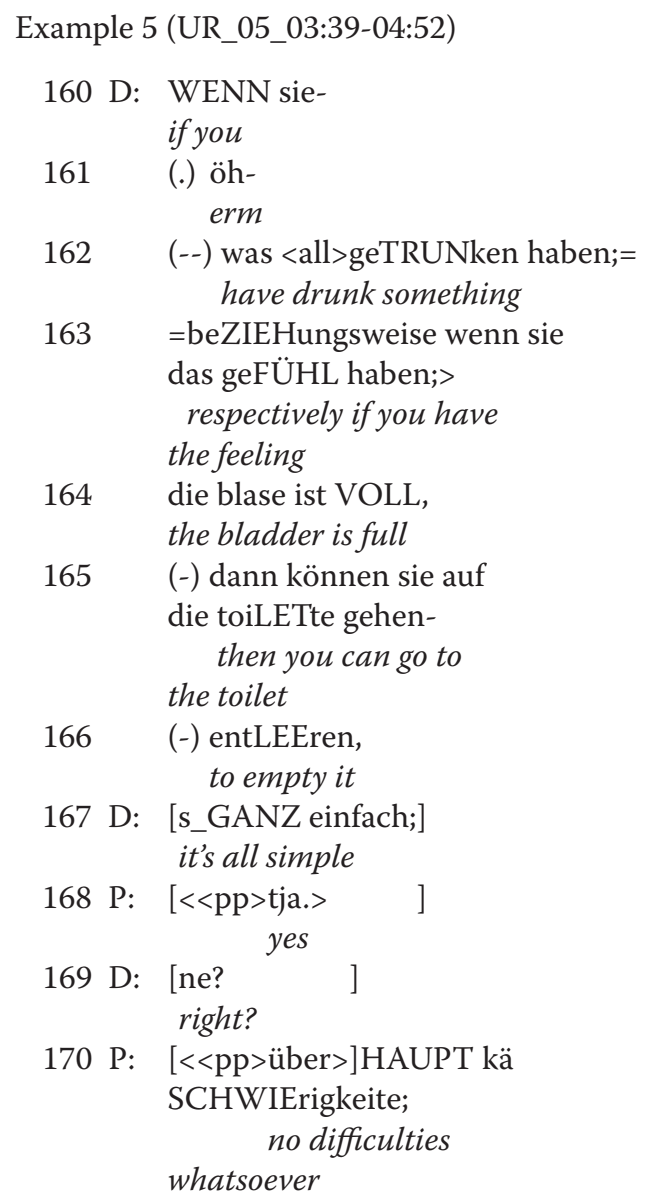

$\rightarrow 171$ D: $\quad(-)<<$ creaky voice $>$ KEIne; $>$

$\rightarrow 172 \quad(-)$ sie setzen sich HIN: und dann LÄUFT_s. you sit down and then it runs

173 P: (-) ja JA;= yes yes

$174=<<$ len,p $>$ und ich $>$ SPÜR $\uparrow$ auch nixand I don't feel anything

The doctor first repeats the negative term ' $k \ddot{a}$ ' (which is dialectal) from the patients turn in line 170 using the standard form 'keine' ('none', line 171). Then he integrates this negative statement with his own event description he had proposed before in lines 
165-166 ('dann können sie auf die toiLETte gehen- (-) entleeren', 'then you can go to the toilet and empty your bladder') into a paraphrase ('sie setzen sich HIN: und dann LÄUFTS', 'you sit down and then it runs', line 172). In this way, the paraphrasing declarative question summarizes a larger stretch of topical talk, using a description which interprets the patient's statement according to the practical purposes of the doctor's exploration. In this case, the doctor reformulates his own first formulation, in which he used professional lexis (line 166 'entleeren'), in a more informal way (line 172 'dann läuft_s'). The practice of paraphrasing often is also used the other way around: the paraphrase extracts the information which is diagnostically most relevant from the patient's turns and puts it into canonical, professional terms (Deppermann 2011). The paraphrasing declarative question makes the doctor's process of practically informed reasoning public to the patient, providing the opportunity to intersubjectively ground and to negotiate the doctor's conclusions via establishing the conditional relevance for a confirmation from the patient, which he provides in line 173, followed by delivering additional details.

Like repeating declarative questions, paraphrasing declarative questions highlight the relevance of some aspect of the topical talk of the patient. In contrast to repeats, however, paraphrases are formulations which display a sensitivity to the different points of view of the interactants. They adapt the patient's talk to the doctor's perspective or to his linguistic register, summing it up and redesigning it according to the practical concerns of the business of history taking (cf. Beach and Dixson 2001). ${ }^{4}$ With these properties, paraphrasing declarative questions can extend the common ground of the participants, mediating prior talk with different perspectives and interactional tasks.

\subsection{Explicative declarative questions}

Like paraphrasing declarative questions, explicative declarative questions formulate the meaning of the patient's prior turn, adapting it to the doctor's frame of reference. They are located more on the transformative end of formulations than paraphrasing declarative questions, because they make implicit meanings of the patient's turn explicit. ${ }^{5}$ They mostly do so by transforming the patient's prior statements according to a psychological frame of relevance. That is, they are used to make emotional and motivational states of the patient explicit, thus being displays of empathy (Ruusuvuori 2005, 2007).
Example 6 (IA_01_00:15-00:20)

03 ich bin nämlich $\uparrow$ SO erKÄ:Ltet; it is because I have such a cold

04 (-) ich [werd ] de erK ÄLtung gar net los:;

I cannot PRT get rid of the cold

05 D: [hmJA,] $m$ yes

$06<<$ p $>$ a:ch du LIEber gott. $>$ oh my god

07 P: <<all>ch_hab se schon>

VIERzehn TA:che; = I already have it for fourteen days

$08 \quad=<<$ dim $>$ hab [ich ] schon hinner mir, $>$ have I already behind me
09 D: [hmJA;
yes
$10 \quad(--)$
$\rightarrow 11$ D: QUÄLT sie $\downarrow_{\text {schon RICHtig; }}$ it really PRT tortures you

12 P: JA<<creaky voice>ja:;> yes yes

$14 \quad(1.2)$

15 D: m:HM, uhum

$16 \quad(--)$

$17 \mathrm{P}: \quad<<$,all $>$ dann hab ich immer schon $>$ HUStentee getrunken und then I have always

18 D: [mhm; ] already drunk tea against the cough

uhum

19 P: [ALles ] abber; (-) and stuff but

20 D: was haben sie denn Außer husten NOCH für be $\downarrow<<$ creaky $>$ schwerden-> which other troubles do you still have apart from cough

In line 11 ('QUÄLT sie schon richtig', 'it really PRT tortures you'), the doctor explicates his understanding that the symptoms the patient reported cause her emotional distress. As his prior evaluative listener's response 'a:ch du lieber gott' ('oh my god', line 06), the explicative declarative question is a display of empathy, which refers back to the whole narrative fragment the patient had produced in lines 03-11. The explicative declarative question invites some elaboration on the patient's psychological condition. As the patient produces only a minimal confirming

\section{equinoxonline}


response ('JA ja:', line 12), the doctor displays his expectation that some elaboration follows by not taking the turn for 1.2 seconds. After that he produces a continuer ' $m: H M$ ' (line 15), which is again followed by a 0.8 seconds pause. Still, she does not align with the proposed shift to the psychological level of the illness. Instead, she continues to report on her attempts to treat her cold (line 18).

Example 7 shows how the doctor uses an explicative declarative question to summarize a lengthy report of the patient in which she describes several symptoms of unease, finishing it with an account why she abandoned her previous ENT.

Example 7 (IA_03_02:17_3:01)

$121 \mathrm{D}$ : is das wie $\mathrm{so}=\mathrm{n} \mathrm{KLO} \beta<<\mathrm{h}>$ gefühl da unten drin,> is it like having a lump down there?

$122 \quad(--)$

123 P: im (RAchen;) in the (throat)

124 (-) da HAB ich (schon/nun) so LANge diesen; for so long I already

have this

125 (-) (ständischen) geSCHMACK; permanent taste

126 (-) von HIER unten, from down here

(...)

$148 \quad(---)<<$ p, all $>$ und dann bin ich auch nimmer HINge $\downarrow$ gangen-= and then I

didn't PRT go there again

149 D: $=<<\mathrm{pp}>\mathrm{mhm}->$ uhum

$150 \mathrm{P}$ : <<all > weil das immer so UMständlich war; clumsy because it was so

151 nach ASCHle[ben $<<$ pp $>$ hinzu $>$ ] fahrn.

to drive to Aschleben

152 D: $\quad[<<\mathrm{pp}>\mathrm{mhm} .>]$

$\rightarrow 153$ D: sie sind EIgentlich so mit ihrem GANzen hals NAsen bereich nicht $\mathrm{zu} \uparrow \mathrm{FRIE}<<\mathrm{t}>$ den.= actually you are kind of not satisfied with your nose throat area

$154 \mathrm{P}:[<<\mathrm{h}>\mathrm{hm}->]$ $h m$

155 D: [=hab ich ] den EINdruck-> is my impression
156 P: (-) nee:-

no

$157<<$ all $>$ HAB ich schon als $>$ KIND

$<<\mathrm{t}>$ immer (mit)->

I have already when I was

a child always (with)

158 (-) [IMmer ] <<dim>

MANdelentzündung und alles;>

always tonsillitis and stuff

159 D: (-) $[<<$ p $>$ Aha, $]$

oh

160 P: o PE:,

surgery

Lines 121-126 are an extract of a lengthy report which the patient gives of pharyngeal problems. With the explicative declarative question sie sind EIgentlich so mit ihrem GANzen hals NAsen bereich nicht $z u \uparrow F R I E<<t>d e n$.' (line 153f., 'actually you are kind of not satisfied with your nose throat area'), the doctor summarizes the patient's report setting it into a psychological frame by focusing on the patient's evaluation of her health condition ('sie sind (...) nicht zufrieden', 'you are not satisfied', line 153). With the modal particle 'eigentlich' ('actually'), the doctor indexes that his formulation draws a generalizing conclusion from the patient's prior turns, and he displays that the attribution of evaluative stance to the patient is his own additional interpretation (' $h a b$ ich den eindruck', 'is my impression', line 155). Thus, the doctor is cautious to display that his evaluative formulation transcends the original statements of the patient. Similar to Example 6, the patient minimally confirms the doctor's understanding ('nee:-', line 156), but does not align with his shift to the psychological frame. Instead, she goes on to report additional symptoms (lines $157 \mathrm{ff}$.). The doctor's explicative declarative question works as a summarizing conclusion, which is successful in terms of an intersubjective definition of the patient's problem area as a weak point in general. This is evidenced by the patient's reaction as she provides additional facts about previous troubles. However, the shift to the psychological plane is not intersubjectively performed, because the patient stays with the description of symptoms.

Doctors use explicative declarative questions to formulate the emotional relevance of the symptoms, observations and events the patient talked about. Such explicative declarative questions change the interactional agenda by interpreting the patient's turns with respect to a psychological frame of reference (cf. Hutchby 2005; Antaki 2008), possibly paving the way for a psychosomatic interpretation of the patient's symptoms. They are a kind of upshot 
formulations (cf. Heritage and Watson 1979), but it is important to note that the declarative question format is only used to explicate meanings which the doctor takes to be implicitly communicated, but not explicitly stated by the patient (Deppermann 2011). It is not used for attributing meanings to the patient which the doctor unilaterally infers, i.e. which are probably not meant by the patient and may not even be acceptable to the patient as an adequate formulation of his/her turns, but which seems to be in place from the doctor's perspective. ${ }^{6}$

In contrast to repeating and paraphrasing declarative questions, explicative declarative questions are not only devoted to checking the doctor's understanding of patient's turns. In addition, they introduce new topical aspects, displaying empathic understanding of the psychological import of the illness for the patient. Since they touch on experiential aspects which the patient did not address, explicative questions can be seen to implicitly claim a deeper or better understanding of the patient than $\mathrm{s} /$ he had expressed him/herself and to invite the patient to expand on the psychological side of the illness (i.e. on cognitions, assessments, emotions, expectations, etc. relating to the illness). Therefore, they can be used as prompts to disclose the psychological background which might provide for a deeper understanding of the illness. Explicative declarative questions could be said to have a psychotherapeutic potential, getting the patient to reflect on psychological aspects of his/her illness s/ he was not aware of or perhaps did not admit yet (see Peräkylä 2008). This potential of explicative declarative questions is, however, very rarely realized in the patient's answers. As in Examples 6 and 7, patients mostly restrict themselves to minimal confirmations. They do not align with the doctor in advancing the psychological agenda. A routine way of dealing with doctor-initiated shifts to a psychological agenda is for the patient to confirm the doctor's psychologising formulation and then shift back to the report of symptoms and related events (like in Examples 6 and 7). The issue of when, how, and why patients do and do not align with a shift to a psychological agenda needs further research which is beyond the scope of this paper.

\section{Discussion}

Prior research has shown that the accomplishment of mutual understanding is a paramount issue in doctor-patient interaction. This task is not only dealt with by interactional practices which are specialized to display understanding, such as response particles, repair and formulations. In this paper, we have shown that doctors also display their understanding of the patient often en passant by interactional practices which are primarily designed to promote interactional progression, namely questions. Thus questions are often used as devices which deal at the same time with two basic, potentially conflicting interactional requirements, i.e. the necessity to secure intersubjectivity and the enterprise of task-oriented interactional progression (cf. Heritage 2007). More specifically, we have seen how doctors use three different syntactic question-formats, i.e. $w$-, V1-, and declarative questions, to display different kinds of understandings and degrees of certainty regarding their current understanding of the patient's problems and their history. By virtue of this property, each syntactic question format is predominantly used in a different stage of topical sequences in history taking: while $w$-and V1-questions open up topical sequences, declarative questions are used to check already achieved understandings and to close topical sequences. The study shows how doctors adapt different syntactic formats of questions flexibly to the common ground which develops between doctor and patient over the course of history taking.

We focused in more detail on three practices of questioning by declarative formulations of the patient's prior turns, namely, repeats, paraphrases and explications. One major function of them is to achieve the confirmation of outcomes of history taking which are relevant for diagnosis and treatment, thus being preferentially used for topical closure and when the doctor has reached diagnostic hypotheses. Still, declarative and V1-questions often project more than confirmation and topical closure. In contrast to prior research, we could show that the expected scope of answers to yes/no-questions and to declarative questions is much less restricted than previously thought. To the contrary, they are often used as prompts to make patients elaborate on already established topics, giving more details or accounting for a confirmation.

Doctors use explicative declarative questions mostly as means of shifting from symptom reports to psychological aspects of the illness and to possible psychosomatic factors. Still, this shift is regularly responded to by patients with minimal confirmation and a shift back to reports on symptoms and to candidate biomedical explanations. This is a noteworthy finding, standing in opposition to the wellestablished claim that doctors favour a biomedical discourse, neglecting life-world concerns which are

\section{eevinoxonline}


related to the illness for the patient (Mishler 1984). The recurrent pattern of patients avoiding expansion on psychological aspects makes us assume that patients orient to a genre-related expectation that doctor-patient interaction has to focus on bodily symptoms and biomedical explanation and treatment. Most patients seem neither ready to disclose confidential psychological information nor to regard doctors as being entitled and competent to deal with psychological aspects. Thus doctors may face a dilemma concerning their displays of how they understand the patient: on the one hand, empathetic displays of the emotional relevance of the illness are vital for establishing rapport and mutual trust and for getting the patient to disclose possibly delicate matters; on the other hand, empathetic displays can be taken by the patient as psychologising and as projecting a psychosomatic interpretation of the illness, which may not be welcome. Consequently, patients may not cooperate in working out the psychological ramifications of the illness. The study shows that displaying and treating understandings in interaction is not only a matter of retrospective correctness. Equally, and perhaps even more importantly, understandings are relevant and are dealt with in terms of which courses of future actions they make available and accountably relevant.

\section{Appendix}

Transcription conventions GAT (Selting et al. 2011)

\begin{tabular}{|c|c|}
\hline [ ] & overlap and simultaneous talk \\
\hline$=$ & latching \\
\hline (.) & micropause (shorter than $0.2 \mathrm{sec}$ ) \\
\hline$(-),(--),(--)$ & $\begin{array}{l}\text { brief, mid, longer pauses of } 0.2-0.5 \text {, } \\
0.5-0.7,0.7-1.0 \mathrm{sec} \text {. }\end{array}$ \\
\hline$(2.85)$ & $\begin{array}{l}\text { measured pause (more than one sec- } \\
\text { ond) }\end{array}$ \\
\hline s_geht & assimilations of units \\
\hline : : : : ::: & $\begin{array}{l}\text { segmental lengthening, according to } \\
\text { duration }\end{array}$ \\
\hline$\ddot{a h h, ~ o ̈ h, ~ e t c . ~}$ & $\begin{array}{l}\text { hesitation signals, so-called 'filled } \\
\text { pauses' }\end{array}$ \\
\hline ، & cut-off with glottal closure \\
\hline so $(h)_{o}$ & laugh particles within talk \\
\hline haha hehe hihi & laugh syllables \\
\hline$(($ lacht $))$ & description of laughter \\
\hline$a k Z E N T$ & strong, primary stress \\
\hline ak!ZENT! & extra strong stress \\
\hline akzEnt & weaker, secondary stress \\
\hline$?$ & pitch-rise to high \\
\hline & pitch-rise to mid \\
\hline & level-pitch \\
\hline
\end{tabular}

pitch-fall to mid pitch-fall to low jump to higher pitch jump to lower pitch low pitch register high pitch register forte, loud fortissimo, very loud piano, soft pianissimo, very soft allegro, fast lento, slow diminuendo, continuously softer inbreath, according to duration outbreath, according to duration para- and extralinguistic activities and events commentaries regarding voice qualities with scope unintelligible according to duration uncertain transcription uncertain sounds or syllables possible alternatives omissions in the transcript (solche/welche)

((...))

\section{Notes}

1. Among the contextual features, the epistemic authority of the addressee regarding the topic (Heritage and Raymond 2005) is the most important factor for the interpretation as a question. The discussion of the precise properties determining the interpretation of declarative sentences as questions is beyond the scope of this paper.

2. Repeats can also be repair-initiators (Schegloff $e t$ al. 1977) which focus on some problematic part of the patient's statements. In this case, declaratives express that the repeated segment violates some expectation of the questioner (indexing surprise, lack of understanding, or doubt). Since the patient has the epistemic authority regarding the experience of his/her illness, however, repair-initiation by doctors is rare.

3. PRT indicates a particle which has no English equivalent.

4. See also (among others) Antaki (2008) and Drew (2003) concerning the 'institutional fingerprint' with which formulations inform interactions.

5. See Heritage (2007) for a discussion of the preferences for progressivity and for achieving intersubjectivity in interaction, which can be in conflict with one another. Explicative declarative questions are a practice which exhibits a simultaneous orientation to both preferences.

6. Such upshots are formulated by doctors in other, more cautious ways than declarative questions, i.e. by framing them as subjective feeling/impression or by asking hypothetical questions (could it be that ..?). 


\section{References}

Antaki, C. (2008). Formulations in psychotherapy. In A. Peräkylä, C. Antaki, S. Vehviläinen, and I. Leudar (eds) Conversation Analysis and Psychotherapy 26-42. Cambridge: Cambridge University Press.

Beach, W. and Dixson, C. (2001). Revealing moments: Formulating understandings of adverse experiences in a health appraisal interview. Social Science \& Medicine 52: 25-45. http://dx.doi.org/10.1016/S0277-9536(00)0 0118-0

Boyd, E. and Heritage, J. (2006). Taking the history: Questioning during comprehensive history-taking. In J. Heritage and D. Maynard (eds) Communication in Medical Care: Interaction between Primary Care Physicians and Patients 151-84. Cambridge: Cambridge University Press.

Clark, H. H. and Schaefer, E. F. (1989). Contributing to discourse. Cognitive Science 13: 259-94. http://dx.doi.org/ 10.1207/s15516709cog1302_7

Deppermann, A. (2011) Notionalization: The transformation of descriptions into categorizations. Human Studies 34 (2): 1551-81. http://dx.doi.org/10.1007/s107 46-011-9186-9

Deppermann, A. and Schmitt, R. (2009). Verstehensdokumentationen: Zur Phänomenologie von Verstehen in der Interaktion. Deutsche Sprache 36 (3): 220-45.

Dowty, D. R. (1989). On the semantic content of the notion of 'thematic role'. In G. Chiercha, B. H. Partee and R. Turner (eds) Prototypes, Types, and Meaning, Vol. II 69-129. Amsterdam: Kluwer. http://dx.doi.org/ 10.1007/978-94-009-2723-0_3

Drew, P. (2003). Comparative analysis of talk-in-interaction in different institutional settings. In P. Glenn, C. D. LeBaron and J. Mandelbaum (eds) Studies in Language and Social interaction 293-308. Mahwah NJ: Erlbaum.

Frankel, R. (1995). Some answers about questions in clinical interviews. In G. H. Morris and R. J. Chenail (eds) The Talk of the Clinic: Explorations in the Analysis of Medical and Therapeutic Discourse 49-70. Hillsdale NJ: Erlbaum.

Heritage, J. (2001). Ad hoc inquiries: Two preferences in the design of 'routine' questions in an open context. In D. Maynard, S. Houtkoop, H. Schaeffer, K. Nora and H. van der Zouwen (eds) Standardization and Tacit Knowledge: Interaction and Practice in the Survey Interview 313-33. New York: Wiley.

Heritage, J. (2007). Intersubjectivity and progressivity in person (and place) reference. In N. Enfield and T. Stivers (eds) Person Reference in Interaction 255-80. Cambridge: Cambridge University Press.

Heritage, J. and Clayman, S. (2010). Talk in Action. Oxford: Wiley-Blackwell. http://dx.doi.org/10.1002/978144 4318135

Heritage, J. and Robinson, J. (2011). 'Some' vs 'any' medical issues: Encouraging patients to reveal their unmet concerns. In C. Antaki (ed.) Applied Conversation Analysis: Changing Institutional Practices 15-31. Basingstoke: Palgrave Macmillan.
Heritage, J. and Watson, R. (1979). Formulations as conversational objects. In G. Psathas (ed.) Everyday Language: Studies in Ethnomethodology 123-62. New York: Irvington.

Hutchby, I. (2005). Active listening: Formulations and the elicitation of feelings-talk in child counselling. Research on Language and Social Interaction 38 (3): 303-329. http://dx.doi.org/10.1207/s15327973rlsi3803_4

Lalouschek, J. (2005). Medizinische Konzepte und ärztliche Gesprächsführung - am Beispiel der psychosomatischen Anamnese. In M. Neises, S. Ditz and T. Spranz-Fogasy (eds) Psychosomatische Gesprächsführung in der Frauenheilkunde - Ein interdisziplinärer Ansatz zur verbalen Intervention 48-72. Stuttgart: Wissenschaftliche Verlagsgesellschaft.

Manning, P. and Ray, G. (2002). Setting the agenda: An analysis of negotiation strategies in clinical talk. Health Communication 14: 451-73. http://dx.doi.org/10.1207/ S15327027HC1404_3

Mishler, E. (1984). The Discourse in Medicine: The Dialectics of Medical Interviews. Norwood NJ: Ablex.

Peräkylä, A. (2008). Conversation analysis and psychoanalysis: Interpretation, affect, and intersubjectivity. In A. Peräkylä, C. Antaki, S. Vehviläinen, and I. Leudar (eds.) Conversation Analysis and Psychotherapy 26-42. Cambridge: Cambridge University Press.

Raymond, G. (2003). Grammar and social organization: Yes/no interrogatives and the structure of responding. American Sociological Review 68 (6): 939-67. http:// dx.doi.org/10.2307/1519752

Rost-Roth, M. (2006). Nachfragen. Formen und Funktionen äußerungsbezogener Interrogationen. Berlin: Mouton de Gruyter.

Ruusuvuori, J. (2005). 'Empathy' and 'sympathy' in action: Attending to patients' troubles in Finnish homeopathic and general practice consultations. Social Psychology Quarterly 68: 204-22. http://dx.doi.org/10.1177/ 019027250506800302

Ruusuvuori, J. (2007). Managing affect: Integrating empathy and problem solving in two types of health care consultations. Discourse Studies 9: 597-622. http://dx.doi. org/10.1177/1461445607081269

Schegloff, E., Jefferson, G., Sacks, H. (1977). The preference for self-correction in the organization of repair in conversation. Language 53 (2): 361-82. http://dx.doi. org $/ 10.2307 / 413107$

Selting, M., Auer, P., Barth-Weingarten, D., Bergmann, J., Bergmann, P., Birkner, K., Couper-Kuhlen, E., Deppermann, A., Gilles, P., Günthner, S., Hartung, M., Kern, F., Mertzlufft, C., Meyer, C., Morek, M., Oberzaucher, F., Peters, J., Quasthoff, U., Schütte, W., Stukenbrock, A., Uhmann, S. (2011). A system for transcribing talkin-interaction: GAT 2. Translated and adapted for English by E. Couper-Kuhlen and D. Barth-Weingarten. Gesprächsforschung 12, www.gespraechsforschung-ozs. de/heft2011/heft2011.htm.

Spranz-Fogasy, T. (2005). Kommunikatives Handeln in ärztlichen Gesprächen - Gesprächseröffnung und Beschwerdenexploration. In M. Neises, S. Ditz and T. Spranz-Fogasy 
(eds) Psychosomatische Gesprächsführung in der Frauenheilkunde. Ein interdisziplinärer Ansatz zur verbalen Intervention 17-47. Stuttgart: Wissenschaftliche Verlagsgesellschaft.

Spranz-Fogasy, T. (2010). Verstehensdokumentation in der medizinischen Kommunikation: Fragen und Antworten im Arzt-Patient-Gespräch. In A. Deppermann, U. Reitemeier, R. Schmitt and T. Spranz-Fogasy Verstehen in professionellen Handlungsfeldern 27-116. Tübingen: Narr.

Stivers, T. (2007). Prescribing under Pressure: PhysicianParent Conversations and Antibiotics. Oxford: Oxford University Press.

Stivers, T. and Heritage, J. (2001). Breaking the sequential mold: Answering 'more than the question' during comprehensive history taking. Text 21(1): 151-85. http:// dx.doi.org/10.1515/text.1.21.1-2.151

Stivers, T. and Majid, A. (2007). Questioning children: Interactional evidence of implicit racial bias in medical interviews. Social Psychology Quarterly 70: 424-41. http:// dx.doi.org/10.1177/019027250707000410

Stivers, T. and Rossano, R. F. (2010). Mobilizing response. Research on Language and Social Interaction 43 (1): 3-31. http://dx.doi.org/10.1080/08351810903471258
Arnulf Deppermann is head of the 'Pragmatics' department at the Institut für Deutsche Sprache and Professor of German Linguistics at Mannheim University. His research interests include conversation analysis, cognition and understanding in interaction, multimodal interaction, positioning in narratives, medical and therapeutic interaction, construction grammar and semantics in talk-in-interaction. His most recent book is Grammatik und Semantik aus gesprächsanalytischer Sicht (2007, de Gruyter). Address for correspondence: Institut für Deutsche Sprache, PF 101621, D-68016 Mannheim, Germany. Email: deppermann@ ids-mannheim.de

Thomas Spranz-Fogasy is member of the 'Pragmatics' department at the Institut für Deutsche Sprache and Professor of German Linguistics at Mannheim University. His areas of research cover conversation analysis, understanding in interaction, semantics in conversation, medical interaction, mediation, argumentation in interaction and interactional rhetoric. (For detailed information see http:// www.ids-mannheim.de/prag/personal/spranz_eng.html). Address for correspondence: Institut für Deutsche Sprache, PF 101621, D-68016 Mannheim, Germany. Email: spranz@ ids-mannheim.de 